\title{
The Weight of Bad Governance in Foreign Mutual Funds
}

\author{
by \\ Linus Wilson \\ Assistant Professor of Finance \\ University of Louisiana at Lafayette \\ B. I. Moody III College of Business \\ Department of Economics \& Finance \\ 214 Hebrard Boulevard, Moody Hall 253 \\ P. O. Box 44570 \\ Lafayette, LA 70504-4570 \\ Phone: (337) 482-6209 \\ Fax: (337) 482-6675 \\ Email: linuswilson [at] louisiana [dot] edu \\ Web: http://www.linuswilson.com
}

This draft: December 2008

First draft: March 2008 


\title{
The Weight of Bad Governance in Foreign Mutual Funds
}

\author{
Abstract \\ Empirical studies show that mutual funds are less likely to hold poorly governed foreign \\ stocks. This theoretical model shows that foreign mutual fund managers will optimally \\ lower their weight of badly governed stocks because they have higher costs of actively \\ managing these holdings than their domestic rivals.
}

Journal of Economic Literature Classifications: G23, \& G34

Keywords: mutual funds, home bias, corporate governance 


\section{Introduction}

Recent studies have documented a propensity for managers of mutual funds to avoid foreign stocks with characteristics of bad corporate governance. Aggarwal et al. (2005) finds that U.S. institutional investors invest less in emerging markets with weak investor protections. In addition, they find institutional investors avoid stocks that have less accounting transparency. Leuz et al. (2009) finds that individual U.S. investors favor stock in foreign companies that are based in countries with strong investor protections, have lower levels of insider ownership, and exhibit low levels of accruals. Das (2008) finds that mutual funds based outside the United States tend to avoid stock in poorly governed firms from different countries than where their fund is based. Mutual funds based in the same country as the stocks that the fund is buying are more likely to hold badly governed firms.

While these studies document empirically that foreign investors avoid poorly governed stocks, the author knows of no formal, partial equilibrium, theoretical model that tests if foreign investors will reduce their portfolio weights in badly governed firms. Chan et al. (2005) presents a general equilibrium model of why investors might tilt their investments towards domestic stocks. Further, that theoretical model does not distinguish between badly and well governed stocks within each country. In contrast, this paper presents a partial equilibrium model of search costs for mutual fund managers when some stocks have characteristics of good corporate governance, and some stocks are poorly governed. This model will be most appropriate for the case where the manager's holdings do not significantly affect the stock price. 
In this paper, a mutual fund manager will have a higher cost of actively managing a portfolio of stocks of companies that conduct business in different languages and under different legal environments. Therefore the costs of actively monitoring the performance of stocks based in other countries will rise for foreign mutual fund managers. Since investors must be more vigilant to catch a slip in performance with less transparent and poorly governed stocks, foreign investors will find active management of poorly governed stocks very costly. This simple, partial equilibrium model finds that when the cost of actively managing badly governed stocks increases, their weight in the mutual fund manager's portfolio will decrease. This explains why there may be an apparent home bias on the part of mutual fund managers as found in the empirical work of Aggarwal et al. (2005), Leuz et. al (2009), and Das (2008).

\section{Model}

Suppose that the $i$-th mutual fund manager earns a passive return on all stocks of $r$ $>0$. This risk-neutral manager can potentially increase her expected returns by actively managing her portfolio. In addition to the passive return of $r>0$ she can increase the expected return on her portfolio by the expected return to a maximum of $R+r$, where $R>$ 0. Suppose that the manager has the choice between allocating her portfolio between poorly governed stocks and well governed stocks. Her portfolio weight in poorly governed, or "badly" governed, stocks is $b_{i} \in[0,1]$. Her portfolio weight in well governed stocks is $1-b_{i}$. The $i$-th manager can raise the probability, $p_{i}$, of earning high returns ( $R$ $+r)$ on a badly governed firms by incurring the cost $\left(\beta_{i} p_{i}^{2}\right) / 2$, where $\beta_{i}>0$. 
Alternatively, she can raise the probability of high returns, $q_{i}$, in her well governed stocks by incurring the cost of active management of $\left(\gamma q_{i}^{2}\right) / 2$, where $\gamma>0$. The probability of just earning the index return before management costs is $1-p_{i}$ on the poorly governed stocks and $1-q_{i}$ on well governed stocks.

The fraction of badly governed stocks in the fund manager's universe is $\theta \in[0,1]$. As the manager tilts her portfolio more towards badly or well governed stocks, she suffers a disutility of specializing more or less in one type of stocks. Namely, by biasing the stocks that she selects towards or away from poorly governed stocks, she is going to make it less likely that she will find highest returning stocks. The cost of biasing her portfolio in an allocation other than the universe of stocks is given by the cost $\left(\delta\left(b_{i}-\theta\right)^{2}\right) / 2$, where $\delta>0$.

We will assume that there are two types of mutual fund mangers. Investing in stocks in countries other than where the fund is based may involve greater costs. Foreign managers, who are based outside the country they are investing in, face language differences and less familiarity with regulation in that foreign country. Further, they may not be abreast of current developments relative to mutual fund managers based in that country. There is some evidence that domestic securities analysts are more productive. Bae et al. (2008) find that securities analysts based in the same country as the company they are studying make significantly more accurate earnings forecasts relative to analysts based in other countries. Let us denote mutual fund managers that invest in foreign stocks by $i=f$ and mutual fund investors that buy domestic stocks by $i=h$. We will assume that mutual fund managers that buy foreign stock find it more costly to actively invest in badly governed stocks than domestic managers. That is, $\beta_{f}>\beta_{h}$. 


\section{Analysis}

The $i$-th manager will attempt to maximize her funds return net of the costs of actively managing her holdings and tilting her portfolio towards a specific segment of the universe of stocks. Chevalier and Ellison (1997) and Sirri and Tufano (1998) document that investors move into mutual funds that experience high past returns. Since mutual fund fees are magnified by the amount of funds invested, the mutual fund manager will be focused on maximizing returns net of her direct costs of management. Her objective function is given by $\rho_{i}\left(q_{i}, p_{i}, b_{i}\right)$. She will maximize this objective function with respect to $q_{i}, p_{i}$, and $b_{i}$, subject to the constraint that all those variables must be between zero and unity.

$$
\max _{\substack{\text { w.r.t.t. } p_{i}, q_{i}, \& b_{i} \\ \text { s.t. } p_{i}, q_{i}, \& b_{i} \in[0,1]}} \rho_{i}=r+b_{i}\left(p_{i} R-\frac{\beta_{i} p_{i}^{2}}{2}\right)+\left(1-b_{i}\right)\left(q_{i} R-\frac{\gamma q_{i}^{2}}{2}\right)-\frac{\delta\left(b_{i}-\theta\right)^{2}}{2}
$$

Given there is an interior solution to this system of equations where $\hat{b}_{i} \in(0,1)$, the solution set takes the following form:

$$
\begin{aligned}
& \hat{p}_{i}=\frac{R}{\beta_{i}} \\
& \hat{q}_{i}=\frac{R}{\gamma} \\
& \hat{b}_{i}=\frac{1}{2 \delta}\left(\frac{R^{2}}{\beta_{i}}-\frac{R^{2}}{\gamma}\right)+\theta
\end{aligned}
$$


Differentiating, $\hat{b}_{i}$ with respect to $\beta_{i}$ we have the following comparative static, which says that the portfolio weight on badly governed firms, $\hat{b}_{i}$, must be decreasing in the cost of actively managing investments in poorly governed stocks, $\beta_{i}$.

$$
\frac{d \hat{b}_{i}}{d \beta_{i}}=-\frac{R^{2}}{2 \delta \beta_{i}^{2}}<0
$$

Equation (3) is unambiguously negative. The proposition follows from the comparative static in equation (3) and the assumption that the costs of active management of badly governed stocks are higher for foreign managers. That is, $\beta_{f}>\beta_{h}$.

\section{Proposition 1}

Given that mutual fund managers actively manage portfolios of both poorly and well governed stocks, domestic managers will hold greater portfolio weights of badly governed stocks than foreign fund managers.

\section{[***Insert figure 1 about here.***]}

In figure 1 , we have specified parameter values $\left\{\gamma, \delta, \theta, R, \beta_{h}\right\}=\{0.1,0.01,0.3$, $0.02,0.1\}$. We have allowed the cost parameter for the foreign manager associated with actively managing stocks in badly governed firms to vary. It must exceed $\beta_{h}=0.1$ because $\beta_{f}>\beta_{h}$. As the comparative static implies, the weight of poor governance 
stocks is declining as the cost of managing those holdings increase. Suppose that the foreign manager had a cost parameter $\beta_{f}$ nearly equal to 0.10 , then the weight of badly governed stocks is $\hat{b}_{h}=0.30^{-}$, or just under 30 percent of her holdings would be in stocks of badly governed firms. Yet, if a foreign manager had a cost parameter of $\beta_{f}=$

0.40 , then she would only hold $\hat{b}_{f}=0.15$, or 15 percent of her portfolio in badly governed stocks.

\section{Conclusion}

This paper presents a theoretical model that shows that the portfolio weights in badly governed stocks should optimally be lower for foreign versus domestic mutual fund managers. This comparative statics analysis is supported by the empirical findings of Aggarwal et al. (2005), Leuz et al. (2009), and Das (2008). 


\section{References}

Aggarwal, Reena, Leora Klapper, and Peter D. Wysocki, 2005, "Portfolio Preferences of Foreign Institutional Investors,” Journal of Banking and Finance, 2919-2946.

Bae, Kee-Hong, Rene' M. Stulz, and Hongping Tan, 2008, “Do Local Analysts Know More? A Cross-Country Study of the Performance of Local Analysts and Foreign Analysts,” Journal of Financial Economics 88, 581-606.

Chan, Kalok, Vincentiu Covrig, and Lilian Ng, 2005, "What Determines the Domestic Bias and Foreign Bias? Evidence from Mutual Fund Equity Allocations Worldwide,” Journal of Finance 60, 1495-1534.

Chevalier, Judith, and Glenn Ellison, 1997, “Risk Taking by Mutual Funds as a Response to Incentives,” Journal of Political Economy 105, 1167-1200.

Das, Praveen, 2008, “The Role of Corporate Governance in Foreign Investment Decisions,” Unpublished Working Paper, University of Wisconsin-Milwaukee.

Leuz, Christian, Karl V. Lins, and Francis E. Warnock, 2009, “Do Foreigners Invest Less in Poorly Governed Firms?” forthcoming Review of Financial Studies. 
Sirri, Erik R. and Peter Tufano, 1998, “Costly Search and Mutual Fund Flows,” Journal of Finance 53, 1589-1622. 


\section{Appendix: Derivation of local maximum in equation (2)}

The first order conditions of the objective function in equation (1) are as follows:

$$
\begin{aligned}
\frac{d \rho_{i}}{d p_{i}} & =\hat{b}_{i}\left(R-\hat{p}_{i} \beta_{i}\right)=0 \\
\frac{d \rho_{i}}{d q_{i}} & =\left(1-\hat{b}_{i}\right)\left(R-\hat{q}_{i} \gamma\right)=0 \\
\frac{d \rho_{i}}{d b_{i}} & =\hat{p}_{i} R-\frac{\beta_{i} \hat{p}_{i}^{2}}{2}-\hat{q}_{i} R+\frac{\gamma \hat{q}_{i}^{2}}{2}-\delta\left(\hat{b}_{i}-\theta\right)=0
\end{aligned}
$$

The interior solutions in equation (2) are derived from solving for the three

unknowns of $\hat{p}_{i}, \hat{q}_{i}$, and $\hat{b}_{i}$ from the three equations in (4) above. The solutions reported are the only solutions in which $\hat{p}_{i}, \hat{q}_{i}$, and $\hat{b}_{i} \in(0,1)$. The second derivatives of this system of equations are given below:

$$
\begin{aligned}
& \rho_{p p} \equiv \frac{d^{2} \rho_{i}}{d p_{i}^{2}}=-\beta_{i} \hat{b}_{i} \\
& \rho_{q p}=\rho_{p q} \equiv \frac{d^{2} \rho_{i}}{d p_{i} d q_{i}}=0 \\
& \rho_{b p}=\rho_{p b} \equiv \frac{d^{2} \rho_{i}}{d p_{i} d b_{i}}=R-\hat{p}_{i} \beta_{i}=0 \\
& \rho_{q q} \equiv \frac{d^{2} \rho_{i}}{d q_{i}^{2}}=-\gamma\left(1-\hat{b}_{i}\right) \\
& \rho_{b q}=\rho_{q b} \equiv \frac{d^{2} \rho_{i}}{d q_{i} d b_{i}}=-R+\hat{q}_{i} \gamma=0 \\
& \rho_{b b} \equiv \frac{d^{2} \rho_{i}}{d b_{i}^{2}}=-\delta
\end{aligned}
$$


The Hession matrix for this set of second order conditions is as follows:

$$
\mathbf{H} \equiv\left(\begin{array}{ccc}
\rho_{p p} & \rho_{p q} & \rho_{p b} \\
\rho_{q p} & \rho_{q q} & \rho_{q b} \\
\rho_{b p} & \rho_{b q} & \rho_{b b}
\end{array}\right)=\left(\begin{array}{ccc}
-\beta_{i} \hat{b}_{i} & 0 & 0 \\
0 & -\gamma\left(1-\hat{b}_{i}\right) & 0 \\
0 & 0 & -\delta
\end{array}\right)
$$

The determinants of the first, second, and third principal minors are the following:

$$
\begin{aligned}
& \left|\mathbf{H}_{1}\right|=\left|\rho_{p p}\right|=-\beta_{i} \hat{b}_{i}<0, \\
& \left|\mathbf{H}_{2}\right|=\left|\begin{array}{ll}
\rho_{p p} & \rho_{p q} \\
\rho_{q p} & \rho_{q q}
\end{array}\right|=\left|\begin{array}{cc}
-\beta_{i} \hat{b}_{i} & 0 \\
0 & -\gamma\left(1-\hat{b}_{i}\right)
\end{array}\right|=\beta_{i} \gamma \hat{b}_{i}\left(1-\hat{b}_{i}\right)>0 \\
& \left|\mathbf{H}_{3}\right|=|\mathbf{H}|=-\beta_{i} \gamma \delta \hat{b}_{i}\left(1-\hat{b}_{i}\right)<0
\end{aligned}
$$

The sufficient condition for an interior maximum requires that the signs of the determinants of the first, second, and third principal minors alternate from negative, to positive, to negative again. This is exactly the case here. Therefore, $\mathbf{H}$ matrix is negative definite, and the sufficient condition for this set of solutions to be a maximum are met. 
Figure 1

the weight of badly governed stocks as a function of the cost of actively managing those holdings

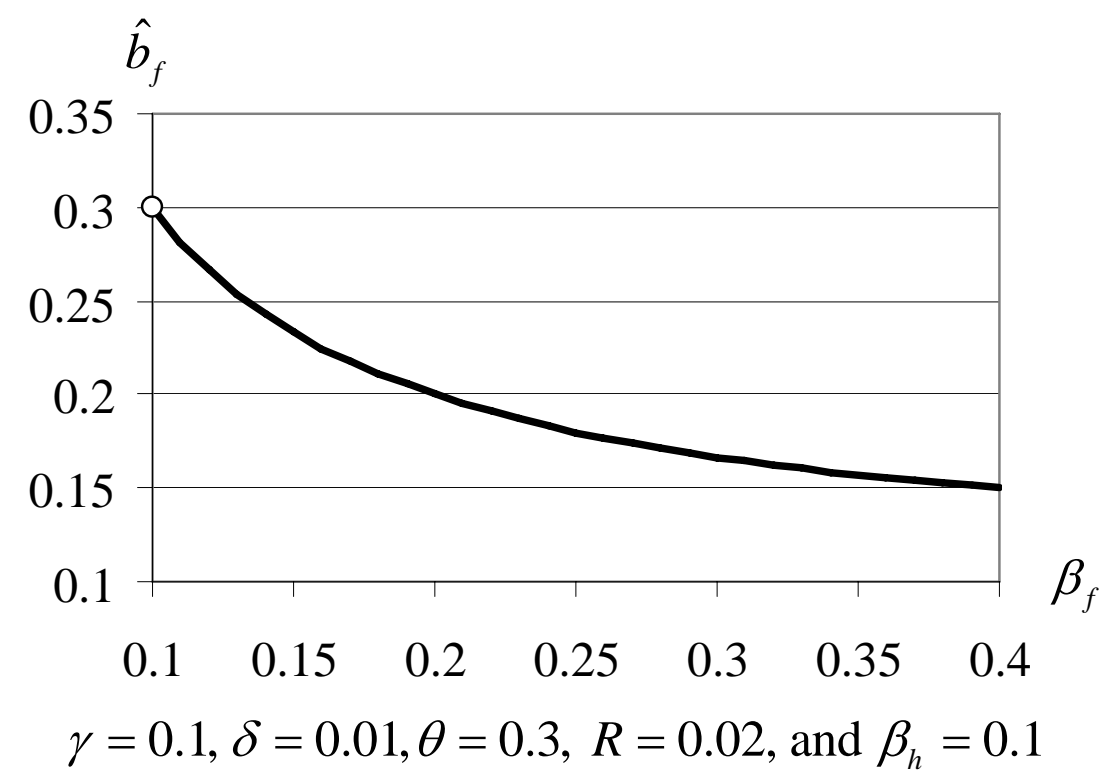

